\title{
Gestational Severe, Nonfamilial Hypertriglyceridemia, Management with İnsulin and Metformin, A Case Report
}

Mazhar Müslüm Tuna*, Faruk Kılınç, Zafer Pekkolay, Hikmet Soylu and Alpaslan Kemal Tuzcu

Department of Endocrinology and Metabolism, Dicle University School of Medicine, Turkey

\begin{abstract}
Severe hypertriglyceridemia is a rare condition in pregnancy. We report a case of gestational, nonfamilial severe hypertriglyceridemia accompanied with gestational diabetes mellitus. Despite an intensive insulin regimen and dietary fat restriction plasma triglyceride levels were remained higher. After a plasmapheresis session, triglyceride levels were reduced nearly $40 \%$. Since plasma glucose and triglyceride levels were higher, metformin therapy was administered. After two weeks of metformin therapy, plasma glucose levels were within target range and triglyceride level was reduced below $1000 \mathrm{mg} / \mathrm{dl}$. She delivered at 38th week of pregnancy via elective cesarean section, a healthy female baby with normal birth weight. Serum triglyceride level decreased immediately to $280 \mathrm{mg} / \mathrm{dl}$ after delivery.
\end{abstract}

Keywords: Gestational diabetes; Hypertriglyceridemia; Metformin

\section{Introduction}

It is well known that plasma lipid levels increase during pregnancy because of increased levels of estrogen, progesterone, and human placental lactogen. However, expected elevations for triglyceride (TG) and total cholesterol levels during a normal gestational period usually do not exceed $332 \mathrm{mg} / \mathrm{dL}$ and $337 \mathrm{mg} / \mathrm{dL}$, respectively, in uncomplicated pregnancies (1). Here, we present a report of 32 years old woman with gestational non-familial, severe hypertriglyceridemia accompanied with gestational diabetes mellitus.

\section{Case Report}

A 32 year old woman was admitted to our department at $27^{\text {th }}$ week of her first pregnancy. She was diagnosed as gestational diabetes mellitus after a $75 \mathrm{gm}$ glucose loading test and recommended of dietary restriction of glucose. She had complaint of mild headache and fatigue. Neither abdominal pain, nor nause and vomiting was reported. No clinical signs, suggestive of hyperlipidemia, such as tendinous xanthomata, lipemia retinalis or other skin lesions were detected. She had a sligtly increased level of triglyceride $(240 \mathrm{mg} / \mathrm{dl})$ and normal cholesterol level, one year before pregnancy and she had no relevant family history. Her Body Mass İndex (BMI) was $27.9 \mathrm{~kg} /$ $\mathrm{m}^{2}$ before pregnancy, and she gained $10 \mathrm{~kg}$ during past two trimesters. Serum lipoprotein profile revealed following findings: TG: 15.600 $\mathrm{mg} / \mathrm{dl}$ (75-220); total cholesterol: $459 \mathrm{mg} / \mathrm{dl}$ (120-220); high density lipoprotein cholesterol (HDL-C): $43 \mathrm{mg} / \mathrm{dl}$ (40-65). Amylase and lipase levels were within normal limits. Abdominal ultrasound imaging was unremarkable with absense of cholelithiasis and all antenatal obstetrical evaluation were normal. Fasting plasma glucose was $126 \mathrm{mg} / \mathrm{dl}$, thyroid, liver and renal function tests were normal. An overnight refrigeration serum sample revealed turbid appearance suggesting the presence of increased Very Low Density Lipoprotein (VLDL) fraction. Intensive insulin therapy and Low Molecular Weight Heparin (LMWH) were administered with medical nutrition therapy (dietary restriction of carbonhidrate and fat (20 gr per day)). After seven days of treatment despite high doses of insulin ( $80 \mathrm{IU} /$ day), blood glucose levels were still above the normal limits and triglyceride level was $12.300 \mathrm{mg} /$ dl. Metformin therapy was started to improve glucose sensitivity and lower triglyceride levels at $850 \mathrm{mg}$ doses once a day and titrated to three times a day. After five days of metformin blood glucose was decreased within the target range while TG level was remained higher despite a significant reduction $(\mathrm{TG}=6200 \mathrm{mg} / \mathrm{dl})$. A therapeutic lipid apheresis, targeting a TG level below $1.000 \mathrm{mg} / \mathrm{dl}$, for preventing acute pancreatitis was performed. After one session of lipid apheresis which was very painfull for the patient TG levels fell from $6.200 \mathrm{mg} / \mathrm{dl}$ to $3460 \mathrm{mg} /$ $\mathrm{dl}$. The following day we suggested an additional apheresis session but she did not approved. She did not tolerate omega -3 fatty acids. Thus, she was treated with intensive insulin therapy, metformin, medical nutrition, excercise and LMWH with close monitoring of plasma triglycerides. Her TG levels ranged from $550 \mathrm{mg} / \mathrm{dl}$ to $880 \mathrm{mg} / \mathrm{dl}$ until delivery. She delivered at $38^{\text {th }}$ week of pregnancy via elective cesarean section a healthy female baby with normal birth weight. Serum TG level decreased immediately to $280 \mathrm{mg} / \mathrm{dl}$ after delivery.

\section{Discussion}

Gestational severe hypertriglyceridemia (HTG) is a very rare disorder with life threatening complications, such as acute pancreatitis, hyperviscosity syndrome and preeclampsia, if left untreated $[1,2]$. Pregnancy, induces severe hyperlipoproteinemia, due to estrogeninduced increase in lipoprotein production and decrease lipoprotein lipase activity in the liver and adipose tissue. The highest level of triglyceride is observed in the third trimester and may rise up to 2-4 times above normal [3-5]. But for most women with normal baseline TG levels and without abnormality in metabolic pathways, such increases are well tolerated. Risk factors for gestational hypertriglyceridemia include the following conditions; obesity, weight gain, hypothyroidism, gestational or nongestational diabetes mellitus, alcohol intake, glucocorticoids and anticonvulsant drugs [6]. Our patient had three of these risk factors that were obesity, weight gain and gestational diabetes mellitus. However, data regarding the association of diabetes mellitus (gestational or

*Corresponding author: Mazhar Müslüm Tuna, Department of Endocrinology and Metabolism, Dicle University School of Medicine, Turkey, Tel: +90 505222 6556; E-mail: tunamazhar@gmail.com

Received September 23, 2014; Accepted November 09, 2014; Published November 16, 2014

Citation: Tuna MM, Kılınç F, Pekkolay Z, Soylu H, Tuzcu AK (2014) Gestational Severe, Nonfamilial Hypertriglyceridemia, Management with Insulin and Metformin, A Case Report. J Diabetes Metab 5: 466 doi:10.4172/2155-6156.1000466

Copyright: ( 2014 Tuna MM, et al. This is an open-access article distributed under the terms of the Creative Commons Attribution License, which permits unrestricted use, distribution, and reproduction in any medium, provided the original author and source are credited. 
pregestational) and hypertriglyceridemia are conflicting. While some experts report a significant association [7-9] others not [10,11]. Underlying genetic mutations including dysbetalipoproteinemia, partial lipoprotein lipase (LPL) deficiency, and ApoE3/3 genotype are also important risk factors for gestational hypertriglyceridemia [12]. However, in carriers of genetic diseases such as LPL deficiency and dysbetalipoproteinemia, pregestational triglyceride levels usually above $1000 \mathrm{mg} / \mathrm{dl}$ and $500 \mathrm{mg} / \mathrm{dl}$, respectively $[6,13]$. Near normal triglyceride levels in our patient, in the pregestational and postpartum period may rule out the possibility of partial LPL deficiency with or without apoE3/ 2 or apoE4/2 genotype. Most causes of HTG are attributable to familial HTG, but nongenetic nonfamilial pregnancy-induced HTG in a patient has been reported previously [14]. However, she had a pancreatitis attack due to severe hypertriglyceridemia, two years before pregnancy, and had a family history of early atherosclerosis. Thus, our patient is unique because of clear data suggest the occurence of gestational, non familial severe HTG. As we stated above, severe HTG in pregnancy has to be treated immediately to prevent acute pancreatite and hyperviscosity syndrome. A very low-fat diet, defined by dietary fat below $20 \%$ of caloric intake, is the mainstay of clinical management of severe hypertriglyceridemia [15]. There are strong evidence that suggest prepregnancy BMI is an important determinant of many pregnancy outcomes. However, the committee recommend that weight loss should be addressed preconceptionally, not during pregnancy, because the safety of intentional weight loss during pregnancy has not been determined [16]. Further reports of severe hypertriglyceridemia during pregnancy have described various other management strategies, including fibrates, omega 3 fatty acids, heparin, intravenous insulin/glucose, parenteral feeding, plasmapheresis and low-density lipoprotein/apheresis [15]. However, data regarding association of statins and teratogenity are limited, it is not recommended to use them during pregnancy [17]. Indeed, statins are still formally contraindicated during pregnancy as categorised X, by FDA. Lipophilic statins (lovastatin, simvastatin) have the most experience and therefore have more evidence related to teratogenic potential. In addition, there is no data for rosuvastatin and pitavastatin regarding their use in pregnancy. Further evaluation is required to assess the possible differences in risk between individual statins [18]. Although, fibrates are contraindicated in pregnancy, there have been a few case reports of the successful use of gemfibrozil, during pregnancy with no side effects particularly in the third trimester $[19,20]$. Metformin improves insulin resistance, and it has been suggested that it influences plasma lipids, independent of glycemic control [21]. In type 2 diabetes, metformin treatment is associated with a reduction in plasma triglyceride, total cholesterol, LDL cholesterol, and VLDL cholesterol concentrations [22]. Moreover, metformin (pregnancy category, B) has been considered as a potentially effective drug in management of gestational diabetes mellitus [23]. However, there is no evidence to suggest the use of metformin in gestational hypertriglyceridemia, yet. To date, our patient is the first published case of non familial gestational severe hypertriglyceridemia treated with metformin succesfully. In conclusion metformin seems to be a safe drug in pregnancy and it worked very well in our case of severe HTG accompanied with gestational diabetes mellitus.

\section{References}

1. Brizzi P, Tonolo G, Esposito F, Puddu L, Dessole S, et al. (1999) Lipoprotein metabolism during normal pregnancy. Am J Obstet Gynecol 181: 430-434.

2. Ray JG, Diamond P, Singh G, Bell CM (2006) Brief overview of maternal triglycerides as a risk factor for pre-eclampsia. BJOG 113: 379-386

3. Gürsoy A, Kulaksizoglu M, Sahin M, Ertugrul DT, Ozer F, et al. (2006) Severe hypertriglyceridemia-induced pancreatitis during pregnancy. J Natl Med Assoc 98: 655-657.
4. Kim HJ, Kalkhoff RK (1975) Sex steroid influence on triglyceride metabolism. J Clin Invest 56: 888-896.

5. Herrera E, Lasunción MA, Gomez-Coronado D, Aranda P, López-Luna P, et al. (1988) Role of lipoprotein lipase activity on lipoprotein metabolism and the fate of circulating triglycerides in pregnancy. Am J Obstet Gynecol 158: 1575-1583.

6. McGladdery SH, Frohlich JJ (2001) Lipoprotein lipase and apoE polymorphisms relationship to hypertriglyceridemia during pregnancy. J Lipid Res 42: 19051912.

7. Koukkou E, Watts GF, Lowy C (1996) Serum lipid, lipoprotein and apolipoprotein changes in gestational diabetes mellitus: a cross-sectional and prospective study. J Clin Pathol 49: 634-637.

8. Rizzo M, Berneis K, Altinova AE, Toruner FB, Akturk M, et al. (2008) Atherogenic lipoprotein phenotype and LDL size and subclasses in women with gestational diabetes. Diabet Med 25: 1406-1411.

9. Sobki SH, Al-Senaidy AM, Al-Shammari TA, Inam SS, Al-Gwiser AA, et al (2004) Impact of gestational diabetes on lipid profiling and indices of oxidative stress in maternal and cord plasma. Saudi Med J 25: 876-880.

10. Butte NF (2000) Carbohydrate and lipid metabolism in pregnancy: norma compared with gestational diabetes mellitus. Am J Clin Nutr 71: 1256S-61S.

11. Kilby MD, Neary RH, Mackness MI, Durrington PN (1998) Fetal and maternal lipoprotein metabolism in human pregnancy complicated by type I diabetes mellitus. J Clin Endocrinol Metab 83: 1736-1741.

12. Basaran A (2009) Pregnancy-induced hyperlipoproteinemia: review of the literature. Reprod Sci 16: 431-437.

13. Mahley RW, Huang Y, Rall SC (1999) Pathogenesis of type II hyperlipoproteinemia (dysbetalipoproteinemia). Questions, quandaries, and paradoxes. J Lipid Res 40: 1933-49.

14. Eskandar O, Eckford S, Roberts TL (2007) Severe, gestational, non-familial, non-genetic hypertriglyceridemia. J Obstet Gynaecol Res 33: 186-189.

15. Goldberg AS, Hegele RA (2012) Severe hypertriglyceridemia in pregnancy. J Clin Endocrinol Metab 97: 2589-2596.

16. Rasmussen KM, Yaktine AL (2009) Institute of Medicine (Committee to Reexamine IOM Pregnancy Weight Guidelines, Food and Nutrition Board and Board on Children, Youth, and Families). Weight Gain during Pregnancy: Reexamining the Guidelines. Washington, DC: National Academy Press: Provides new guidelines for weight gain during pregnancy that are based on minimizing the risks of inadequate or excessive gains to mothers as well as their infants.

17. Hosokawa A, Bar-Oz B, Ito S (2003) Use of lipid-lowering agents (statins) during pregnancy. Can Fam Physician 49: 747-749.

18. Godfrey LM, Erramouspe J, Cleveland KW (2012) Teratogenic risk of statins in pregnancy. Ann Pharmacother 46: 1419-1424.

19. Al-Shali K, Wang J, Fellows F (2002) Successful pregnancy outcome in a patient with severe chylomicronemia due to compound heterozygosity for mutant lipoprotein lipase. Clin Biochem 35: 125-30.

20. Saadi HF, Kurlander DJ, Erkins JM, Hoogwerf BJ (1999) Severe hypertriglyceridemia and acute pancreatitis during pregnancy: treatment with gemfibrozil. Endocr Pract 5: 33-36.

21. Wulffelé MG, Kooy A, de Zeeuw D, Stehouwer CD, Gansevoort RT (2004) The effect of metformin on blood pressure, plasma cholesterol and triglycerides in type 2 diabetes mellitus: a systematic review. J Intern Med 256: 1-14.

22. Reaven GM, Johnston P, Hollenbeck CB, Skowronski R, Zhang JC, et al (1992) Combined metformin-sulfonylurea treatment of patients with noninsulindependent diabetes in fair to poor glycemic control. J Clin Endocrinol Metab 74: 1020-1026.

23. Goh JE, Sadler L, Rowan J (2011) Metformin for gestational diabetes in routine clinical practice. Diabet Med 28: 1082-1087. 